\title{
EDUCAÇÃO LITERÁRIA E EDUCAÇÃO PARA AS RELAÇÕES ÉTNICO- RACIAIS: UMA EXPERIÊNCIA DE EDUCAÇÃO A DISTÂNCIA ${ }^{1}$
}

\author{
LITERARY EDUCATION AND EDUCATION FOR THE ETHNIC-RACIAL \\ RELATIONS: AN EXPERIENCE OF DISTANCE EDUCATION
}

\author{
Denise Naccari ${ }^{2}$ \\ Eliane Santana Dias Debus ${ }^{3}$ \\ Maria Aparecida Rita Moreira ${ }^{4}$
}

\section{Resumo}

Embora a LDB apresente em seu artigo 26-A o ensino da literatura afro-brasileira como obrigatório, pouco se tem feito para capacitar os professores e professoras a contemplar a leitura dos escritores e escritoras afro-brasileiros no currículo escolar. No intuito de formar multiplicadores para o ensino dessa literatura, foi elaborado um curso na modalidade a distância. Essa proposta foi apresentada aos professores e professoras da rede pública estadual de Santa Catarina que trabalham com o Ensino Médio através do Educad (Educação Continuada à Distância), espaço que tem por objetivo proporcionar Formação Continuada aos professores das diferentes disciplinas curriculares da Educação Básica e faz parte do portal da Secretaria de Educação (SED) do Estado de Santa Catarina. O curso intitulado A literatura no contexto da sala de aula - trabalhando com contos, realizado no período de 28 de abril de 2011 a 12 de agosto de 2011, totalizou 120 horas e atingiu um público final de cinquenta e oito professores. Para tanto, utilizou diferentes ferramentas, entre elas: fóruns, questionários, tarefas, diários. A participação dos cursistas foi muito positiva, uma vez que mais de $50 \%$ dos iniciantes concluíram o curso. A boa avaliação dos cursistas a respeito do curso, bem como seus depoimentos, demonstraram que a educação a distância pode ser utilizada para auxiliar na capacitação de professores e professoras.

Palavras-chave: educação a distância; literatura afro-brasileira e angolana, educação literária.

\section{Abstract}

\footnotetext{
${ }^{1}$ O curso de formação a distância foi elaborado para auxiliar no desenvolvimento da tese que propõe discutir a proposição de uma nova educação literária, pelo viés da diversidade, aos professores e professoras da rede pública de SC, para que sejam multiplicadores de uma proposta pedagógica, estética e política comprometida com a luta anti-racista no Brasil. Portanto, dados presentes nos itens 1.1 e 1.2, relacionados ao curso de formação a distância citado neste artigo, integram a sua tese de doutorado da profa. Maria Aparecida Rita Moreira, doutoranda em teoria literária pela UFSC.

${ }^{2}$ Professora da Secretaria de Estado da Educação de Santa Catarina. Graduação - licenciatura e bacharelado - em ciências Sociais pela Universidade Federal de Santa Catarina (1985). Especialização em Gestão de Tecnologias Aplicadas à Educação. Doutoranda em teoria literária pela Universidade Federal de Santa Catarina-UFSC.

${ }^{3}$ Professora da Universidade Federal de Santa Catarina, atuando no Departamento de Metodologia de Ensino e no Programa de Pós-Graduação em Educação. Líder do Grupo de Pesquisa LITERALISE: Grupo de Pesquisa em Literatura Infantil e Juvenil e Práticas de Mediação Literária, da UFSC. Doutorado em Linguística e Letras pela Pontifícia Universidade Católica do Rio Grande do Sul (2001). E-mail: elianedebus@hotmail.com

${ }^{4}$ Doutoranda em teoria literária pela Universidade Federal de Santa Catarina-UFSC. Mestre em Letras Inglês pela UFSC. Lotada na Secretaria de Educação e Inovação do Estado de Santa Catarina.
} 
Although LDB (an specific Law that gives orientation to Brazilian education) in its article 26-A shows African literature teaching as compulsory, few things have been done to empower teachers for using African Brazilian writers inside their classroom. In order to prepare trainer to multiply the African literature teaching was organized a distance learning course. This project was presented to the state school teachers from Santa Catarina from high school through Educad (continuum distance learning), a place which goal is to promote distance learning to teacher from different subjects and belongs to 'Portal da Secretaria de Educação do Estado de Santa Catarina'. The course received the title Literature within the meaning of the classroom working with short stories, and was carried out from the twenty eighth of abril 2011 to the twelfth of august 2011, adding up 120 hours of course, and fifty eight teachers finished the course. During the course teachers could work with different tools, such as, foruns, questionnaires, tasks, diaries. The students participation was positive, since $50 \%$ those who began the course finished it. The students evaluation was also positive, they gave statements which demonstrate their appreciation to distance education to improve their learning.

Keywords: Afro-Brazilian literature, distance education, teachers.

\title{
A literatura afro-brasileira e angolana no contexto de sala de aula - uma experiência de formação continuada
}

\begin{abstract}
Entre numa livraria, na biblioteca da escola, numa bienal do livro, ou se aproxime da estante de livros de sua casa. Agora, separe os que possuem personagens negros. (LIMA, 2005, p. 102).
\end{abstract}

As palavras de Heloisa Pires Lima, pesquisadora e escritora para crianças e jovens, remetem ao silenciamento que, por muito tempo, repercutiu nos acervos literários das bibliotecas escolares brasileiras. Os livros literários que apresentam personagens negras ainda perfazem uma quantidade ínfima no mercado editorial, embora se tenha constatado um crescimento da produção que tematiza a cultura africana e afro-brasileira, em particular para o público infantil e juvenil (DEBUS, 2012). Esse crescimento decorre da publicação da Lei 10.639/2003 e das Diretrizes Curriculares Nacionais para a Educação das Relações Étnico-Raciais e para o ensino de História e Cultura Afro-Brasileira e Africana (2004), que criaram uma demanda mercadológica.

Se a discussão, no plano temático, sobre aspectos da africanidade e afrobrasilidade nos textos ficcionais ainda é recente, em particular também pela constituição de um acervo, mais embrionária é a reflexão sobre a produção literária produzida pelas mãos de escritores afro-brasileiros e africanos. Nesse sentido, podemos falar em uma escrita afro-brasileira? 
A resposta a essa pergunta não é resolvida de pronto, mas temos já, no Brasil, um grupo de pesquisadores que vem centrando seus estudos no que poderíamos chamar de construção de uma literatura afro-brasileira, com o mapeamento dos escritores e de suas produções. Nesse campo, podemos elencar os trabalhos de Edimilson de Almeida Pereira (2012) e de Eduardo Assis Duarte e Maria Nazareth Soares Fonseca (2011), que buscam trazer à cena os escritores afro-brasileiros de ontem e de hoje, evidenciando suas produções.

Questiona-se, contudo: esse conhecimento sobre a produção literária de escritores africanos e afro-brasileiros reverberaria no espaço escolar? Teriam os professores do Ensino Médio, foco de nossos estudos, conhecimento sobre essa produção? Com essas inquietações, pretendendo entrelaçar saberes, na tentativa de construir uma proposta de diálogo entre a educação literária e a educação para as relações étnico-raciais, a partir da mediação dos professores de Língua Portuguesa da rede pública estadual de Santa Catarina, elaboramos um curso de formação direcionado a esses profissionais.

Assim, no intuito de atingir um maior número possível de professores e professoras e acreditando que "as tecnologias interativas, sobretudo, vêm evidenciando, na educação a distância, o que deveria ser o cerne de qualquer processo de educação: a interação e a interlocução entre todos os que estão envolvidos nesse processo" (MORAN s/d), optamos pela formação na modalidade a distância. Justifica-se nossa escolha, pois muitos dos interessados trabalhavam distantes da capital, o que dificultaria a realização de um curso presencial. Entendíamos que, desse modo, possibilitávamos a interação de educadores de diferentes regiões do Estado, a partir da leitura de textos literários de escritores e escritoras brasileiros contemporâneos, comprometidos com uma literatura afro-brasileira, e de escritores e escritoras angolanos. Nesse sentido, partilhamos o pensamento de Moran (s/d - A) quando afirma que:

\footnotetext{
A educação a distância, antes vista como uma modalidade secundária ou especial para situações específicas, destaca-se hoje como um caminho estratégico para realizar mudanças profundas na educação como um todo. É uma opção cada vez mais importante para aprender ao longo da vida, para a formação continuada, para a aceleração profissional, para conciliar estudo e trabalho.
}

O parágrafo aqui transcrito reafirma a nossa crença de que é possível a interação, o debate, o fazer pedagógico a distância. Ao mesmo tempo, conscientes de que este fazer não poderia ser mera transposição dos cursos presenciais, e fundamentados, 
principalmente, nos textos de José Manuel Moran, procuramos construir algo novo, com diferentes espaços de aprendizagem, de modo a motivar os professores a interagirem em um curso que apresentasse “[...] mais do que conteúdo, [...]” que se mostrasse como espaço de “[...] pesquisa, troca, produção conjunta” (MORAN, s/d - B).

Nesse sentido, o curso desenhado em 2010 foi aplicado no primeiro semestre de 2011, enquanto experiência-piloto, para um grupo de 82 professores que atuavam no Ensino Médio da rede pública estadual de Santa Catarina, conforme passamos a expor.

\subsection{Por dentro do curso}

O curso encontrou amparo e justificativa na Lei 10.639/2003 que inclui, no currículo oficial da rede de ensino pública e privada, a obrigatoriedade da temática "História e Cultura Afro-Brasileira". Essa abordagem coloca a literatura ao lado da arte e da história, como disciplinas prioritárias para o ensino dessa temática. Também, ampara-se nas Diretrizes Curriculares Nacionais para a Educação das Relações ÉtnicoRaciais e para o Ensino de História e de Cultura Afro-Brasileira e Africana. No que se refere à fundamentação teórica, pautamo-nos pelas teorias relacionadas à literatura afrobrasileira e às literaturas africanas de língua portuguesa. Consideramos, ainda, as implicações do racismo na sociedade e na escola.

Para o desenvolvimento do curso, foi utilizado o EDUCAD (Educação Continuada a Distância), recurso criado a partir do Moodle, em 2008, disponível no portal da Secretaria de Educação (SED) do Estado de Santa Catarina, com o objetivo de proporcionar Formação Continuada aos professores das diferentes disciplinas curriculares da Educação Básica. Essa modalidade, no mesmo instante em que permite otimizar tempo, recursos e ampliar a abrangência, exige metodologia e técnicas diferenciadas para garantir o sucesso desse processo, que é mais complexo do que a relação direta professor/aluno numa sala de aula tradicional.

Iniciamos nosso trabalho com uma proposta de suporte ao curso de Formação para uso de Laboratórios Didáticos Móveis de Física e Química - LDM. Em 2009, criamos um espaço para o grupo envolvido na Formação dos Saberes da Terra. Além do curso de que estamos tratando, outros dois foram direcionados a professores de Língua Estrangeira - Inglês. Podemos, então, afirmar que esses cursos, antes criados, nos deram 
certeza de que este é um bom caminho a seguir, considerando os resultados mais do que satisfatórios, na opinião daqueles que aceitaram o desafio.

Para a realização efetiva do curso, houve uma construção, a seis mãos, das três autoras deste texto: Maria Aparecida, professora do Ensino Médio da Rede Estadual de Educação e acadêmica do Programa de Pós-Graduação em Literatura, em nível de doutorado, desenhou os módulos e atuou como professora/tutora da turma; Eliane Santana Dias Debus, professora do Departamento de Metodologia de Ensino, do Centro de Ciências da Educação da Universidade Federal de Santa Catarina, assessorou e coordenou o projeto; e Denise Naccari, professora especialista, atuando na Secretaria de Estado da Educação, responsável pelo EDUCAD, respondeu por toda parte administrativa e pelos recursos tecnológicos, dando suporte aos professores na utilização desse ambiente.

A chamada dos professores para o curso aconteceu por meio de uma Circular Interna, encaminhada às 36 Gerências Regionais de Educação ${ }^{5}$, e da divulgação no portal da Secretaria ${ }^{6}$. A partir da divulgação do curso, foi realizada, em março de 2011, a pré-inscrição, sendo que quatrocentos e setenta (470) professores demonstraram interesse. Apesar do grande número de interessados, somente 100 vagas foram abertas, devido à falta de recursos financeiros para a contratação de tutores.

Quando do início do curso, como nem todos os selecionados responderam à mensagem de convocação, encaminhada via e-mail, fizemos uma segunda chamada para as vagas remanescentes, sendo que oitenta e dois (82) entraram no ambiente virtual e realizaram a primeira tarefa. Destes, 58 concluíram o curso.

O número final de participantes, praticamente $70 \%$ dos cursistas que iniciaram a formação, foi considerado pela equipe organizadora bastante relevante, levando em consideração que a maioria dos participantes trabalhava 40 horas semanais ou mais, e muitos vivenciaram a greve no magistério público de mais de trinta dias, que aconteceu no período em que o curso se realizava. Ressaltam-se, também, as dificuldades relacionadas à educação a distância, tais como: a ausência ou a pouca familiaridade com

\footnotetext{
5 A Secretaria de Estado de Educação de Santa Catarina/SED está descentralizada em 36 Gerências Regionais (GEREDs), que operam como coordenadorias regionais.

${ }^{6}$ A SED dispõe de site institucional onde registra suas notícias, programas, ações, entre outras atividades de cunho institucional, denominado Portal da Educação.
} 
a utilização de e-mail, dificultando o contato $^{7}$ com os cursistas, ainda, o desconhecimento das ferramentas do moodle. Muitos professores e professoras não estão habituados à educação a distância e, ao se colocarem no papel de alunos, nesta modalidade, encontraram dificuldades. Como esclarece Moran (s/d - C), ao falar sobre as dificuldades,

Entrar em ambientes virtuais silenciosos, cheios de materiais e ferramentas, os deixa confusos. A falta de conversa com pessoas reais, ao vivo, os assusta. O ambiente digital para quem não está acostumado é confuso, distante, pouco intuitivo e agradável.

Desse modo, os professores, participantes dessa formação, além de trabalharem com um conteúdo que para muitos era desconhecido, tiveram que enfrentar as dificuldades em lidar com as ferramentas tecnológicas.

\subsection{Da construção do curso}

O curso apresentado no EDUCAD contou com seis módulos e recebeu o título $A$ literatura no contexto da sala de aula: trabalhando com contos. Os objetivos principais dessa formação continuada foram: (1) introduzir o gênero narrativo conto; (2) apresentar textos que tratassem da literatura brasileira, numa perspectiva afro-brasileira; (3) proporcionar o contato com as literaturas africanas de língua portuguesa, sendo escolhida, entre elas, a angolana, oferecendo um panorama desta; e (4) proporcionar o contato com contos afro-brasileiros e angolanos de diferentes autores.

Os módulos utilizaram variados recursos, disponíveis no EDUCAD, como por exemplo, fóruns, que proporcionaram a maior interação entre os cursistas; questionários, que permitiram aos professores e professoras momentos de leituras direcionadas; diário de bordo, um diário reflexivo com a proposta de (re)pensar posicionamentos frente à construção do racismo no Brasil, além de outros espaços de interação e debate.

Apresentaremos, a seguir, de maneira resumida, os conteúdos trabalhados nos módulos.

\footnotetext{
${ }^{7}$ No caso específico desse curso, o acesso era feito por e-mail institucional. Muitos dos professores e professoras selecionados não possuíam esse e-mail. Para esses, foram criados e-mails e enviados, posteriormente, aos mesmos para que tivessem acesso ao EDUCAD.
} 
O módulo 1 apresentou o vídeo que traz a contação de história “A menina que fazia azeite de Dendê”, realizado por Augusto Pessôa ${ }^{8}$, e teve como objetivo inserir o tema no ambiente de formação, bem como aproximar os participantes um pouco mais do ritual que envolve a narrativa oral, fortemente presente na cultura africana.

O módulo 2 buscou apresentar aos professores aspectos teóricos sobre o conto, e, para isso, nos apoiamos, principalmente, em Nádia Battella Gotlib (1985).

O módulo 3, por sua vez, trouxe os respectivos contos selecionados de escritores brasileiros: “Olhos d’água” e “Zaíta esqueceu de guardar os brinquedos”, de Conceição Evaristo; “A descida”, de Júlio Emílio Brás; “Uma furtiva lágrima”, de Nei Lopes; "Boneca”, de Cuti; e "O menino e o livro", de Georgina Martins. Os contos selecionados de escritores angolanos foram os seguintes: "Nós choramos pelo cão tinhoso" e "Palavras para o velho abacateiro", de Ondjaki; "Discurso sobre o fulgor da língua” e "Falsas recordações felizes”, de Agualusa; “Os dois Amigos”, de Maria Celestina Fernandes; e "Violência”, de João Melo.

Após a leitura dos contos pelos cursistas, foram propostas atividades que buscavam motivá-los a interagir com os textos literários apresentados e com seus escritores e escritoras.

Para a concretização do módulo 3, foi realizado um levantamento de escritores e escritoras angolanos. Entre os inúmeros escritores e escritoras mapeados, foram escolhidos para fazer parte deste estudo: José Luandino Vieira, José Eduardo Agualusa, Ondjaki, Maria Celestina Fernandes e, posteriormente, João Melo. Este foi incorporado ao curso devido à dificuldade que os professores tiveram de encontrar, em suas escolas, o livro Contos Africanos de Língua Portuguesa, distribuído às escolas brasileiras pelo Plano Nacional de Biblioteca nas Escolas (PNBE) do Ministério da Educação, do qual faz parte o conto de Luandino Vieira.

Os escritores brasileiros foram selecionados, primeiramente, pela autoria e, em seguida, pela temática. Importante lembrar que o curso de formação A literatura no contexto de sala de aula: trabalhando com contos aconteceu no modo a distância, através de plataforma virtual, portanto, para veiculação dos contos, houve necessidade de reunir aqueles que tivessem cópias digitalizadas disponíveis na internet. Nessa linha

\footnotetext{
8 A contação foi apresentada através do Youtube. Disponível em: $<$ http://www.youtube.com/watch?v=STQeHo3U1Fc\&feature=related $>$. Augusto Pessôa é ator, cenógrafo, figurinista, arte educador, dramaturgo e contador de histórias.
} 
de pensamento, o grupo de escritores brasileiros foi composto por Conceição Evaristo, Júlio Emílio Brás, Cuti, Nei Lopes e Georgina Martins.

Entre os contistas angolanos, foi possível encontrar textos literários de Maria Celestina Fernandes, Agualusa, Ondjaki e João Melo, disponíveis para download na União dos Escritores Angolanos.

Com relação aos brasileiros, o escritor Cuti possui um site ${ }^{9}$, onde seus contos e poemas podem ser lidos. Os contos que não foram encontrados digitalizados foram postados no curso, mediante autorização dos escritores(as), com exceção de Luandino Vieira, cujo conto faz parte do livro "Contos Africanos de Língua Portuguesa”, distribuído às escolas brasileiras pelo Plano Nacional de Biblioteca nas Escolas (PNBE) do Ministério da Educação.

No módulo 4, foram trabalhadas questões teóricas referentes à literatura afrobrasileira e à literatura angolana. Também problematizamos o conceito de raça no Brasil. Para tanto, selecionamos vários textos, entre eles: Literatura e Afrodescendência, de Eduardo de Assis Duarte, sobre literatura afro-brasileira; Laura Cavalcanti Padilha: Uma fiandeira da voz e da letra, de Laura Padilha (entrevista), focando literatura angolana; um vídeo do Youtube, intitulado Café com Leite: Água e Azeite, sobre as questões raciais no Brasil.

No módulo 5, apresentamos aos cursistas uma proposta para a realização de um projeto pedagógico, tendo por base todo material trabalhado durante o curso. Solicitamos aos cursistas que desenvolvessem o projeto em equipe. Para a realização dessa tarefa, foi realizado, primeiramente, um fórum de discussão, onde foram postadas e desenvolvidas trocas de ideias. Para a finalização do projeto, os cursistas usaram a ferramenta Wiki, que propicia a construção de texto coletivo.

Moran (s/d) lembra que "Boa parte dos cursos de EAD não consegue recriar o ambiente de grupo, criar vínculos, que os alunos se conheçam e conversem entre si.” Ao sugerir um trabalho em grupo, pretendeu-se romper com a ideia de que a educação a distância está ligada a um trabalho individualizado, mostrando aos professores que é possível negociar, criar um texto, um projeto, coletivamente.

Alguns professores tiveram dificuldades na realização da atividade em grupo virtualmente e optaram pelo trabalho individual; outros aceitaram o desafio e conseguiram finalizar a atividade de acordo com a proposta inicial.

\footnotetext{
${ }^{9}$ http://www.cuti.com.br/ - último acesso em 24 de novembro de 2011
} 
O módulo 6 foi o de encerramento e permitiu que os cursistas tivessem acesso a um fórum, no qual postaram suas impressões sobre o curso e responderam a um questionário de avaliação. Tanto no fórum quanto no questionário, as avaliações apontaram para um resultado positivo, como podemos observar pelos depoimentos apresentados a seguir, retirados do Fórum Palavras finais.

Por X - quinta, 4 de agosto de 2011, 10:14:

Quero, sinceramente, parabenizar todos que, tão gentil e responsavelmente, nos conduziram durante esses meses. Com greve, com desânimo, sem vontade de prosseguir.

Já fiz inúmeros cursos de aperfeiçoamento, mas nenhum me enriqueceu tanto quanto este. Muitas ideias pré-formadas que eu tinha sobre educação a distância vieram por terra, felizmente.

Valeu, mesmo. Finalmente aprendi algo depois de tantos cursos inúteis. O prazer de aprender está latente na gente e só nos damos conta disso quando nos deparamos com pessoas que levam a sério aquilo a que se propuseram. Parabéns a todos nós.

Por Y - quinta, 4 de agosto de 2011, 00:26:

"Você ganha força, coragem e confiança a cada experiência em que enfrenta o medo. Você tem que fazer exatamente aquilo que acha que não consegue.” Eleonor Roosevelt.

Colegas cursistas e valorosas professoras, obrigada pela maravilhosa oportunidade desse curso. Na profissão professor(a) é muito bom participar de aprendizagens que podem, definitivamente, nos auxiliar a mudar a ordem das coisas positivamente.

Pelos depoimentos, percebe-se que os professores encontraram no curso um aparato metodológico que lhes possibilitou refletir sobre o exercício da literatura de temática africana e afro-brasileira, em particular a literatura produzida por escritores africanos.

\section{Conclusões}

O curso de capacitação para professores e professoras de língua portuguesa da rede pública do estado de Santa Catarina coloca-se como uma proposta possível de levar a literatura afro-brasileira para o espaço escolar.

Os contos apresentados no curso podem, sem sombra de dúvidas, nortear a discussão de uma educação literária pelo viés da educação para a relação étnico-racial.

Constatamos que a construção de uma educação literária, comprometida com a educação para as relações étnico-raciais, é viável e tem amparo legal. Contudo, 
recordamos que já se passaram dez anos desde que a lei 10.639 foi promulgada e, ainda, não percebemos mudança significativa no currículo escolar, nem sequer nas disciplinas de arte, história e literatura brasileiras, no que concerne ao conteúdo da lei e de suas diretrizes. O grande desafio é fazer com que as escolas brasileiras insiram a literatura afro-brasileira nos conteúdos ensinados.

Ao encerrarmos o curso, tivemos a satisfação do dever cumprido. Apesar das dificuldades, dos 59 cursistas que responderam ao questionário de avaliação, 54 afirmaram que o curso atendeu, totalmente, a suas expectativas; 5 , que atendeu com restrições. Apenas 10 revelaram ter tido dificuldade em encontrar as atividades oferecidas no curso.

Ressaltamos, aqui, o depoimento de uma das cursistas, no fórum de encerramento:

\footnotetext{
"Agradeço a oportunidade, os encaminhamentos dados pelas tutoras, as contribuições dos colegas cursistas. Enfim, a possibilidade de poder conhecer um pouco mais da arte da palavra! A possibilidade de conhecer e valorizar a produção angolana no gênero "conto".

Foi muito bom e já tem gosto de saudade!”
}

A frase final da cursista nos remete ao pensamento de José Manuel Moran (s/d B): “Um bom curso é aquele que nos entristece quando está terminando e nos motiva para encontrarmos formas de manter os vínculos criados.”

\section{Referências}

DEBUS, Eliane Santana Dias. A escravização africana na literatura infantil e juvenil: lendo dois títulos. Currículo sem Fronteiras, v.12, nº1, pp. 141-156, Jan/Abr 2012. Disponível em: <www.curriculosemfronteiras.org>. Acesso em: 25 set. 2012.

DUARTE, Eduardo Assis; FONSECA, Maria Nazareth Soares. Literatura e afrodescendência no Brasil: Antologia Crítica. Belo Horizonte: UFMG, 2011.

LIMA, Heloise Pires Lima. Personagens negros: um breve perfil na literatura infantojuvenil. In: MUNANGA, Kabengele (Org.). Superando o Racismo na escola. 2. ed. Brasília: SECAD/MEC, 2005, p. 102.

MORAN, José Manuel. O que é educação a distância. s/d. Disponível em: <http://www.eca.usp.br/prof/moran/dist.html>. Acesso em: 25 out. 2012.

A educação a distância como opção estratégica. s/d-A. Disponível em: $\overline{<\mathrm{http}: / / w w w . e c a . u s p . b r / m o r a n / e s t r a t e g i c a . h t m l>. ~ A c e s s o ~ e m: ~} 20$ out. 2012. 
O que é um bom curso a distância? s/d-B. Disponível em: <http://www.eca.usp.br/prof/moran/bom_curso.htm>. Acesso em: 20 out. 2012.

Por que a Educação a Distância avança menos do que esperado? s/d-C. Disponível em: <http://www.eca.usp.br/prof/moran/menos.pdf>. Acesso em: 20 out. 2012.

PEREIRA, Edimilson de Almeida. Panorama da literatura afro-brasileira. Disponível em: <http://www.letras.ufmg.br/litefafro>. Acesso em: 05 jan. 2012. 